\title{
Ecological Management as a factor of Mining Region Development
}

\author{
Natalia Egorova ${ }^{1, *}$, Natalia Zaruba $^{1}$, Tatyana Jurzina ${ }^{1}$, and Valery Tumin ${ }^{1}$ \\ ${ }^{1}$ T.F. Gorbachev Kuzbass State Technical University, 650000, 28 Vesennyaya street, Kemerovo, \\ Russia
}

\begin{abstract}
The article studies new approaches to management of regional eco-economic systems in conditions of strong impact on the ecological component of region economy; gives the assessment of influence of relationship between industrial enterprises and territories of their presence; offers tools of realization of corporate social responsibility in the management system of regional eco-economic systems. Environmental problems in the mining region, are especially sharply felt today in the conditions of the current state of economy. This challenge that will require if the wording to use a number of measures of preventive character, in particular use of instruments of realization of the mechanism of social responsibility of business for sustainable social and economic development of the territory. The organizational and economic mechanism will allow to carry out the trial functions providing sustainable social and economic development of territories, acting in the form of the coordinated interaction of the elements providing strengthening of points of body height of functioning of regional ecologic and economic systems.
\end{abstract}

\section{Introduction}

Today and in the long term sustainable social and economic development of regions increasingly depend not just on accumulation of earlier created social and economic resources, but also on search and implementation of new solutions helping to approach the territory management problems in an integrated manner. Such solutions, on the one hand, are intended to offer territories additional opportunities for attraction of investments and further effective development, on the other hand, to provide life of quality both to present and future generations living in an industrial region.

Technogenic influence of activity of business structures on a surrounding medium and environmental risks, associated with coal mining, define need of realization of a complex of the actions directed to decrease in the negative impact on ecology of the territory of presence. There are important conditions for this to happen: reduction of harmful emissions, rational use and sewage disposal, utilization and processing of a waste, conservation of biodiversity of the territory.

\footnotetext{
${ }^{*}$ Corresponding author: egorovann@list.ru
} 
Such approach becomes even more relevant in conditions of strengthening of ecological tension, increasing in dependence of region economy development on the environment state. The need to consider management of the region from the point of view of ecoeconomic system management becomes natural and obvious.

\section{Materials and Methods}

Famous Russian economist and ecologist M.Lemeshev defined eco-economic system as "the integration of economy and nature representing interconnected and interdependent functioning of social production and behavior of natural processes in nature and in biosphere particularly", assuming rather national level of interpretation of eco-economic systems (EES) [7].

Modern economic literature offers the most various renderings of the eco-economic system category and various aspects of modeling and further functioning of EES. In this regard it is possible to specify works of such authors as A.Jacobson, N.Chepurnykh, V. Razumovsky, I. Yurina, etc.

Despite distinction of authors' approaches to EES, we will agree with O.Yudakhina that the backbone characteristic of EES is regionality, at the same time, we consider that regional eco-economic systems act as an object of management which is under the influence of the management system for ensuring harmonious integration of economic and ecological aspects of development.

Such EES representation at the territorial level or even in certain regions and industrial complexes is very important for practical realization of the principles and methods of management.

Additionally, many authors consider the primary environmental management Wednesday as one of the challenges and opportunities for business development [1].

It should be noted that the approach to management of region economy as REES is especially relevant for territories with anthropogenous impact on environment. The designated problem has been already considered in scientific works of a number of authors $[2,4-6,8-15]$.

Born S. M defines a comprehensive approach to environmental management and planning, which will in our view be more rational and accelerated development of regional ecological-economic systems [3].

We consider it necessary to carry the Kemerovo region to such territories. It continues to remain an industrial region with prevalence in heavy industries, in particular, mining industry.

In the region economy, structure the dominant position is held by the following industries that negatively influence ecology and are connected with production and processing of natural recourses of the territory: coal mining, chemical industry, ferrous and nonferrous metallurgy. Their share, together with power industry, the industry of construction materials, and forest and woodworking industries, in the regional industrial structure of economy in 2016 made more than $96 \%$.

At the same time, the coal branch (owing to raw materials) historically takes key positions within development of the region and its social and economic stability. In the regional branch structure the coal branch is prevailing (specific weight makes $31.4 \%$ ) and respectively is the main source of Gross Regional Product and budget replenishment. The connected industries, such as ferrous and nonferrous metallurgy, also take prevailing positions in the total volume of branches and together make about $40 \%$, as a result the economy structure has $70 \%$ of productions directly connected with coal mining.

It is necessary to emphasize that mining enterprises are the main sources of waste formation. It is known that production of one tone of coal is followed by formation from 
three to twenty tones of solid waste and emissions of methane in the atmosphere from 5 to $25 \mathrm{~m}^{3}$. At the same time because of mining operations fertile lands are damaged and brought out of farming business, small rivers and natural reservoirs are destroyed.

The enterprises of metallurgical and chemical industry also vent a large amount of gaseous, solid and liquid waste consisting mostly of carbon oxide, nitrogen dioxide, sulfur dioxide, sulphurous anhydride, ammonia and other toxic compounds.

Production and processing of regional natural resources, especially coal, in the foreseeable future will remain the main factor of sustainable development of the region as the abovementioned branches are, so-called, branches of specialization, and define its place in the systems of Russian and international division of labor. They will continue to make negative impact on air and water, soil, flora and fauna of the territory, though in the reduced size, thanks to introduction of scientific and technical achievements in the production sphere and toughenings of environmental legislation.

In conditions of strong impact on the ecological component of the regional economy, there is an urgent need to apply the eco-economic analysis of relationship between industrial enterprises and territories of their presence (environment), coordinating requirements to development and management of regional eco-economic systems. As a result, ecologization of decision-making should become a key aspect in the management system of regional eco-economic systems.

\section{Results and Discussion}

Being one of the REES subjects, an industrial enterprise, pursuing, first, the purposes of profit making and increase in competitiveness, quite often negatively influences REES in general. The bodies of central and local government can propose countermeasures, which should include certain measures directed to protection of ecological interests of the region, preservation of natural resources and the whole basis for reproduction of society activity.

Such measures should be based on refusal of the technogenic mechanism of REES management, when there is only an elimination of negative ecological consequences in ecology of the territory of the business presence.

In our opinion in modern conditions the combination of stimulating and administrating mechanisms of REES management is directed to use of new technologies, economy of natural resources together with economic market tools, and it should lead to creation of positive eco-economic environment for stimulation and development, including agriculture and rural territories of the industrial region.

At the same time we consider use of the mechanism of corporate social responsibility for elimination of ecological negative impact at implementation of business activity most expedient.

Use of tools of the mechanism of social responsibility will allow creating conditions for effective "ecologization" of business entities' activity and improvement of their financial and economic state.

In simple words, it is possible to assume that there is a functional dependence between optimum decision-making in REES management and tools of the mechanism of corporate social responsibility, which can be presented as follows:

$$
Y=\left\{X_{1}, X_{2}, X_{3} \ldots X_{n}\right\}
$$

where $X_{1}, X_{2}, X_{3}, \ldots . X_{n}$ - tools of the mechanism of realization of corporate social responsibility in the territory of presence.

We consider such tools are: social investment, social marketing, social corporate technologies, social brand, social help, municipal and private partnership. 
The designated tools of the mechanism of realization of corporate social responsibility work in optimization of administrative decisions by regional eco-economic systems, namely in prevention or decrease in ecological damage to the territory of presence, improvement of economic indicators of an industrial enterprise, the main socio-economic indexes of the region, and, therefore, all regional eco-economic system.

\section{Conclusion}

Thus, the success of REES management and, accordingly, social and economic development of the territory in many respects depends on that how effectively administrative solutions of the problems, accompanying processes of use of natural and economic capacity of the territory, are developed and realized.

In our opinion it is important to combine economic and ecological components of all regional system and they should be directed at the following:

- decrease in impact of business on ecology and reduction of ecological damage;

- decrease in material, financial, resource losses as a result of carrying out of actions of the mechanism of corporate social responsibility;

- increase in competitiveness, both of the enterprise and the territory in general where business activity is carried out.

\section{References}

1. J. R. Beaumont, Managing the environment: business opportunity (BAES, London., 2000)

2. W. Beller, Sustainable development and environment management (UNESCO, Paris, 2001)

3. S. M. Born, Integrated environmental planning and management: moving from theory to practice (BAES, London, 1999)

4. S. N. Vassilyev, V. A. Baturin, A. V. Lakeyev, Proceedings of IEEE International Conference on Systems, 5, 339 (1993)

5. N. Zaruba, N. Egorova, P. Kosinskij, E3S Web Conf., 15, 04003 (2017)

6. N. A. Zaruba, N. N. Egorova, Coal in the 21st Century: Mining, Processing and Safety, 1, 39 (2016)

7. R. G. Lee, Adaptive management: promises and pitfalls (University of Arizona Press, Tucson, 2000)

8. M. I. Lemeshev, N. B. Chepurnyh, N. P. Jurina, Regional environmental management: towards harmony (PM: Thought, London, 1986)

9. M. Marion Environmental issue and sustainable futures: a critical guide (MIT Press, Cambridge, 2000)

10. A. Mas-Colell, M. D. Whinston, J. R. Green, Microeconomic theory (Oxford Univ. Press, New York, 1995)

11. M. Podesto Environmental assessment: transition of a decision system to the environmental management of projects (OUP, Oxford, 2001)

12. F. M. Riceiardi, Top Management Decision Simulation: the AMA Approach (American Management Association, New York, 1957) 
13. H. Siebert, Economics of the environment: theory and policy (Springer, Berlin, 1992)

14. E. A. Fedulova, A. V. Medvedev, P. D. Kosinskiy, S. A. Kononova, P. N. Pobedash, Foods and Raw Materials, 4:1, 154 (2016)

15. G. Zipf, Human behavior and the principle of least effort (Addison-Westley, Cambridge, 1949) 